\title{
"Who is the Best Player of Table Tennis Champions" is the Innovation of National Fitness
}

\author{
Zhiping LI \\ Physical Department Civil Aviation University of China
}

\begin{abstract}
Who is the best player" is an important innovation to promote the national fitness. The successful development of this activity has played a positive role in the increase of sports population, the kindness degree of show, the expansion of hosting right and the increase of economic benefit as well as the bridge construction of friendship in mainland China, Hongkong, Macao and Taiwan. In other words, there is no doubt that "who is the best player" has played a positive role in promoting the overall development of national fitness.
\end{abstract}

Index Terms - table tennis, badminton, champions

\section{Introduction}

Under the background of the study on national fitness and with Chinese table tennis tournament as the platform, this paper focuses on promoting national fitness and improving physical strength of the citizen. At the same time, it also emphasizes on building friendly ties among three places to build a friendship bridge.

\section{2."Who is the best player" and the innovation of sports population}

In August 5, 2013, the State Sports General Administration held a press conference in Beijing, announcing "Sampling Survey Results of Fitness Activities and Physical Conditions of people from 20 years old to 69 years old in 2013". The survey contents include the questionnaire and the physical test, involving 28 indicators such as the daily physical fitness behaviors, the body shape, the physical functions and the physical quality, etc. 43629 valid samples have been obtained from 243 streets (towns) in 30 cities of 10 provinces and there are 1636063 effective data. The survey results show that $49.2 \%$ of people have participated in physical fitness in the past year, in which there are $59.8 \%$ of urban residents and $35.6 \%$ of rural residents. The proportion of the urban and rural residents who regularly participate in physical fitness has reached $32.7 \%$ and it has improved $4.5 \%$ compared with the previous survey [1].

With the nationwide development of "who is the best player" of Chinese folk table tennis and badminton tournament, the table tennis and the badminton have become more popular and there are more people participating in these activities. At the same time, the folk table tennis clubs and badminton clubs have been significantly increased. Taking Meixian as the example, before broadcasting "who is the best player", the number of people who can regularly participate in badminton was around 1500. However, the number has reached to 6000 after broadcasting "who is the best player" of folk badminton tournament, which has almost increased five times compared with the previous number. It is fully demonstrated that the competition of "who is the best player" has promoted the sports population [2].

\section{3. "Who is the best player" is the innovation of "seeing and touching"}

From January 6 to January 10 in 2014, five reports on "Thoughts of Development of Sports Reform in Depth and Breadth" have been published in Sports Edition of "People's Daily", which focused on the aspects of "public sports service", "folk sports" and "bigger picture of sports development". At the same time, the lack of public sports service has been discussed and the suggestions such as "justifying the community sports organizations" and "reconstructing rather than repairing the sports development mode" have been proposed [3]. In 2013, the spurt demand and the vigorous vitality of folk sports were encouraging and enlightening. Especially in 2013-2014, some grassroots enthusiasts have come on the big stage through "who is the best player-table tennis and badminton folk tournament". The audiences are elated and the grassroots compete with each other. The whole process is thrilling and it is full of ups and downs. This competition has strong geographical characteristics and civil features. The strong local flavor is closer to the people and they can see their familiar friends, colleagues and ball friends to enter into the studio hall of CCTV. This competition is aimed at the grassroots table tennis and badminton lovers and these grassroots can give full play to their sports competition levels. The civilian populations are motivated and the situation that the sports events can be seen and they cannot be touched will be changed [4].

4. "Who is the best player" is the innovation of the fusion of Olympic champion, world champion and best folk player

In addition to the deep impression left by "who is the best player", it is also found that the sports events demand the interactivity. "Who is the best player" has been divided into several zones. For example, the table tennis competition includes eastern area, northeast area, northern area, northwest area, southwest area and southern area. The coaches of each area are consisted of the former world champion and Olympic champion. The chief coaches of six areas are respectively Shi Zhihao, Kong Linghui, Liu Guoliang, Wang Tao, Xu Shaofa and Guo Yuehua. They will offer some professional guidance and training. The players will compete with each other in the final competition in Beijing. The famous player Bao Chunlai, 
who is regarded as the chief coach of six areas, is very popular in launching ceremony of "who is the best player" competition. Bao Chunlai and the Athens Olympic champion Zhang Jun have accepted the challenge of two amateurs, which fully reflects the communication of thoughts and feelings, the communication of skills and tactics and the communication of different social backgrounds among the former world champion, the Olympic champion and the grassroots. These communications are contributing to the development and the promotion of harmonious society.

In the final competitions of table tennis and badminton tournaments, there exist the direct challenges between world champions and grassroots. Taking table tennis as the example, in the final competition of "who is the best player", there is a special section-star challenge. The adult male and female champions have the opportunity to challenge the world champion. The challenge opponents are Wang Liqin and Liu Shiwen. The result is determined by a game and the grassroots can be given seven points in advance. It is indicated that Wang Liqin and Liu Shiwen will fall behind the grassroots in the beginning. In this case, firstly, the suspense and the sightseeing value of competition will be increased; secondly, the distance between world champion and grassroots will be shortened; thirdly, the concept that the world champions come from the common people can be reflected.

\section{5."Who is the best player" is the innovation of tournament hosting right}

In 2013-2014, "who is the best player" of table tennis and badminton folk tournaments is a competition that is well organized by CCTV sports channel, Chinese table tennis association and badminton association. It is hosted by CCTV sports entertainment Co., LTD. The idea that the mass sports should not be arranged by government has become the consensus, which is also the direction for sports department to transform the government functions. With the development of Sports in our country, the sports competitions have shown a diversified development trend. However, how to hold a competition and the competition for whom have become unavoidable issues, which are also the key problems in the reform of sports competitions [5]. No matter how the sports develop in depth, returning to public and serving the public are the origins of sports events. Then, the market value and the social value of sports competitions can be truly reflected. No doubt, this grassroots competition hosted by CCTV sports channel will gradually subvert the traditional concept of Chinese sports fans [6].

\section{6."Who is the best player" is the innovation of economic benefit}

This competition produces the attention economy. The title, the venue and the clothes of "who is the best player" are obtained the commercial sponsorship. The economic value has exceeded the ones of table tennis and badminton tournaments in which some Olympic champions and world champions have participated. For example, Dongfeng Citroen has developed the special vehicles in addition to the title sponsorship; at the same time, they have also offered the oil cards, the free cars, the car equipment and the badmintons. In Jinghai competition area of Tianjin province, Tiens Groups have invested 2 million yuan to sponsor this badminton competition. Based on estimation, in the eight competition areas, the total sponsorship amount is more than 320 million yuan, which is a high degree that the top table tennis and badminton competitions are difficult to achieve.

7. "Who is the best player" is the innovation of the three places to build a friendship bridge

There are seven players participating in "who is the best player" of table tennis competition in southern zone from Hongkong, Macao and Taiwan regions. Their common feature refers to the rich conditions. However, the love for table tennis has never been changed due to the changes of material conditions. Through the table tennis competition, they have deeply understood the customs of mainland, the regional cultures and the long historical background of Chinese nation. In the men's single match of badminton folk tournament in southern zone, the player Song Mingxun from Taiwan has defeated 13-year-old teenager Wanghao with two points in advance. He has obtained a precious opportunity to participate in the final competition on behalf of southern zone. In the team competition, Hong Kong and Macao peak badminton club is against Guangdong Huayusansheng Company. After the men's singles, mixed doubles and women's singles competitions, Hong Kong and Macao players have the opportunities to participate in the final competition with one point in advance. According to the incomplete statistics, the number of people from Hong Kong, Macao and Taiwan is more than 200. Their common desire is to pass the competitions, make more friends, enhance skills, deepen understandings and promote communications. At the same time, they also hope to narrow the distance of the three places and promote more frequent exchanges as well as the prosperity of the Chinese descendants. Suggestions:

1. "Who is the best player" of table tennis and badminton tournament should be titled by Taiwan brands, Hong Kong brands and Macao commercial brands so as to improve the brand awareness and increase the economic trade in the three places.

2. It is required to develop "who is the best player" competition in the business circles of Taiwan, Hong Kong and Macao so as to increase the contacts of the three places as well as the trade exchanges.

3. It is necessary to develop "who is the best player" competition in the schools of the three places in order to cultivate the friendship among teenagers.

\section{Conclusion}

"Who is the best player" is an important innovation to promote the national fitness. The successful development of this activity has played a positive role in the increase of sports population, the kindness degree of show, the expansion of 
hosting right and the increase of economic benefit as well as the bridge construction of friendship in mainland China, Hongkong, Macao and Taiwan. In other words, there is no doubt that "who is the best player" has played a positive role in promoting the overall development of national fitness.

\section{Acknowledgment}

I want to pay tribute to all the experts and workers whose dedicated efforts have made this paper possible. My thanks also go to the institutions for their great help.

\section{References}

[1] Baidu net: National Sports Population Census, 2010,3,22.
[2] Baidu net: Xiamen National Conference on Sports Instructors.

[3] Zhan Wendu. On Raising the National Affinity of China towards the Outside World. Journal of Guangdong University of Foreign Studies. 2009. 7 (4): 14.

[4] Li Shudong. "Grassroots" Dream Lifted by National Platform. China Newspaper Industry. 2013, 8:12.

[5] Xiao Linpeng. Construction of Chinese National Image Based on the Sport Perspective. Journal of Shenyang Sport University, 2013, 2 (1): 12-17.

[6] Jia Zuozhang. Reform and Opening Up Policy Makes China More Approachable. China Newspaper Industry. 2012.2 (the second volume):209-210.

[7] Panmin. Current Situation of Sports Venues in China. Sports, 2010, 9 (5): 152-154.

[8] Chinese Social Sciences Net: National Sports Association Analysi. 